\title{
Association between vascular endothelial growth factor gene polymorphisms and bladder cancer risk
}

\author{
YANFENG YANG, XUEPEI ZHANG, DONGKUI SONG and JINXING WEI \\ Department of Urology, The First Affiliated Hospital of Zhengzhou University, Zhengzhou, Henan 450000, P.R. China
}

Received October 30, 2013; Accepted January 9, 2014

DOI: $10.3892 / \mathrm{mco} .2014 .296$

\begin{abstract}
Vascular endothelial growth factor (VEGF) gene polymorphisms are associated with susceptibility to a number of cancers. The present case-controlled study aimed to investigate the correlation between VEGF gene polymorphisms and the risk of bladder cancer. The effects of VEGF polymorphisms were investigated in patients with bladder cancer and healthy controls in our hospital between May, 2008 and May, 2013. Peripheral blood samples were obtained from 480 patients with bladder cancer and 420 healthy controls. The polymerase chain reaction-restriction fragment length polymorphism technique was used to detect three VEGF gene polymorphisms (rs3025039 C/T, rs833052 C/A and rs1570360 G/A) in these subjects. The genotype and allele frequencies were also investigated in order to determine their association with stage, grade and histological type of bladder cancer, as well as smoking status. Our results suggested that the frequency of the rs833052 AA genotype was significantly higher in patients with bladder cancer [odds ratio $(\mathrm{OR})=1.75 ; 95 \%$ confidence interval (CI): $1.05-2.92 ; \mathrm{P}=0.03$ ] compared to that in healthy controls. There was no significant correlation between the rs833052 AA genotype and bladder cancer stage, grade or histological type, whereas smoking was identified as a risk factor for bladder cancer in the included patients $(\mathrm{OR}=1.48$; 95\% CI: 1.13-1.93; $\mathrm{P}=0.004)$. The rs3025039 and rs1570360 gene polymorphisms were not found to be correlated with the risk of bladder cancer or its progression. In conclusion, our results suggested that the VEGF rs833052 C/A polymorphism
\end{abstract}

Correspondence to: Dr Jinxing Wei, Department of Urology, The First Affiliated Hospital of Zhengzhou University, 1 Jianshe East Road, Zhengzhou, Henan 450000, P.R. China E-mail: weijingxing2001@outlook.com

Abbreviations: VEGF, vascular endothelial growth factor; PCR, polymerase chain reaction; SNP, single-nucleotide polymorphism; $\mathrm{OR}$, odds ratio; $\mathrm{CI}$, confidence interval

Key words: vascular endothelial growth factor, single-nucleotide polymorphism, bladder cancer, polymerase chain reaction restriction-fragment length polymorphism, case-control study may be associated with a modest increase in the risk of bladder cancer in Chinese individuals.

\section{Introduction}

Urinary bladder cancer is the most common urinary tract malignancy. Over 70,000 individuals in the United States were diagnosed with urinary bladder cancer in 2012, of whom $>14,880$ succumbed to the disease, making urinary bladder cancer the sixth most common type of cancer (1). A number of risk factors for bladder cancer have been established, including cigarette smoking, exposure to industrial aromatic amines and the uptake of drugs, such as phenacetin, cyclophosphamide and chlornaphazine $(2,3)$. Smoking was found to be a principal independent risk factor for bladder cancer (4). Despite the decrease in smoking rates in the US, the age-adjusted incidence rates for bladder cancer in men and women have remained the same or have marginally increased since the 1980s (5). Genetic polymorphisms in a number of metabolic enzymes were found to act as modulators of bladder cancer risk $(6,7)$.

Angiogenesis is a process essential for tumor growth, invasion and metastasis (8). Vascular endothelial growth factor (VEGF) is a potent endothelial cell-specific regulator of angiogenesis, which affects the egress of plasma proteins and cells that directly and indirectly stimulate angiogenesis. Additionally, the overexpression of VEGF in a variety of solid tumors was correlated with a poor prognosis $(9,10)$. The VEGF gene is located on chromosome $6 \mathrm{p} 21.3$ and consists of 8 exons. Thus far, 30 single-nucleotide polymorphisms (SNPs) of VEGF have been described (11), several of which were found to affect its expression (12), including the widely investigated rs3025039 (also referred to as $+936 \mathrm{C} / \mathrm{T}$ ) in the 3 ' untranslated region, as well as rs833052 and rs1570360 in the promoter region. These SNPs have been implicated in susceptibility to several types of tumors, including renal and gastric cancers $(13,14)$.

The present hospital-based case-control study aimed to investigate the potential modifying effects of these three polymorphisms on VEGF in a Chinese population. To the best of our knowledge, only one previous study reported the association between VEGF polymorphisms and susceptibility to bladder cancer in Spain (15), while epidemiological studies have yet to investigate the effects of VEGF polymorphisms on bladder cancer in other ethnic groups. 
Table I. Clinical characteristics and risk factors in patients with bladder cancer and healthy controls.

\begin{tabular}{|c|c|c|c|}
\hline Characteristics & Cases $(n=480)$ & Controls $(n=420)$ & P-value \\
\hline \multicolumn{4}{|l|}{ Gender, no. (\%) } \\
\hline Male & $272(56.7)$ & $218(51.9)$ & 0.15 \\
\hline Female & $208(43.3)$ & $202(48.1)$ & 0.15 \\
\hline Age, years $\pm S D$ & $54.4 \pm 7.8$ & $53.6 \pm 8.4$ & 0.46 \\
\hline \multicolumn{4}{|l|}{ Smoking status, no. (\%) } \\
\hline Smoker & $226(47.1)$ & $158(37.6)$ & $<0.01$ \\
\hline Non-smoker & $254(52.9)$ & $262(62.4)$ & $<0.01$ \\
\hline \multicolumn{4}{|l|}{ Tumor stage, no. (\%) } \\
\hline Superficial (Tis-T1) & $189(39.4)$ & - & - \\
\hline Invasive (T2-T4) & $291(60.6)$ & - & - \\
\hline \multicolumn{4}{|l|}{ Tumor grade, no. (\%) } \\
\hline Low (G1+G2) & $338(70.4)$ & - & - \\
\hline High (G3) & $142(29.6)$ & - & - \\
\hline \multicolumn{4}{|c|}{ Histological type, no. (\%) } \\
\hline Papillary & $392(81.7)$ & - & - \\
\hline Non-papillary & $88(18.3)$ & - & - \\
\hline
\end{tabular}

\section{Materials and methods}

Study subjects. Between May, 2008 and May, 2013, a total of 420 healthy volunteers and 480 patients with bladder cancer from The First Affiliated Hospital of Zhengzhou University (Zhengzhou, China) were enrolled in this study. All the cases were histopathologically confirmed and staged according to the tumor-node-metastasis staging system of the Union for International Cancer Control. The tumors were graded according to the World Health Organization classification. Information regarding gender, age, lifetime tobacco exposure and tumor histopathology was obtained from medical records. The patients were defined as non-smokers (patients who smoked $<100$ cigarettes over their lifetime) or smokers.

The study protocol was approved by the Ethics Committee of The First Affiliated Hospital of Zhengzhou University. Written informed consent was obtained from all the participants according to the Declaration of Helsinki.

DNA extraction and genotyping. Peripheral blood samples were obtained from the two groups. DNA was extracted using the QIAamp DNA Blood Mini kit (Qiagen, Valencia, CA, USA). The rs3025039, rs833052 and rs1570360 gene polymorphisms were then determined using a polymerase chain reaction $(\mathrm{PCR})$-restriction fragment length polymorphism assay using the following primers: 5'-AAGGAAGAG GAGACTCTGCG-3' (forward) and 5'-TATGTGGGTGGG TGTGTCTA-3' (reverse); 5'-ACGTTGGATGTAGAA AACACAGCGACTGGC-3' (forward) and 5'-ACGTTG GATGTACCAGGCTTGAAATGACAG-3' (reverse); and 5'-GCCCGAGCCGCGTGTGGAA-3' (forward) and 5'-GCCCGAGCCGCGTGTGGAG-3' (reverse), respectively. The PCR program for the rs3025039 amplification consisted of an initial denaturation step at $95^{\circ} \mathrm{C}$ for $2 \mathrm{~min}$, followed by 35 cycles of $30 \mathrm{sec}$ at $95^{\circ} \mathrm{C}, 30 \mathrm{sec}$ at $67^{\circ} \mathrm{C}, 30 \mathrm{sec}$ at $55^{\circ} \mathrm{C}$ and a final elongation at $72^{\circ} \mathrm{C}$ for $5 \mathrm{~min}$. The PCR program for the rs833052 amplification consisted of an initial denaturation step at $94^{\circ} \mathrm{C}$ for $10 \mathrm{~min}$, followed by 45 cycles of $20 \mathrm{sec}$ at $94^{\circ} \mathrm{C}, 30 \mathrm{sec}$ at $56^{\circ} \mathrm{C}, 1 \mathrm{~min}$ at $72^{\circ} \mathrm{C}$ and a final elongation at $72^{\circ} \mathrm{C}$ for $3 \mathrm{~min}$. The PCR program for the rs1570360 amplification consisted of an initial denaturation step at $96^{\circ} \mathrm{C}$ for $1 \mathrm{~min}$, followed by 10 cycles of $15 \mathrm{sec}$ at $96^{\circ} \mathrm{C}, 30 \mathrm{sec}$ at $56^{\circ} \mathrm{C}$, $50 \mathrm{sec}$ at $61^{\circ} \mathrm{C}$ and a final elongation at $72^{\circ} \mathrm{C}$ for $40 \mathrm{sec}$. The PCR products were digested with the appropriate restriction enzymes (New England Biolabs, Inc., Beverly, MA, USA); specifically, NlaIII, AclI and MnlI were used to digest the rs3025039, rs833052 and rs1570360 PCR products, respectively. The digested PCR products were then analyzed on $3 \%$ agarose gel and stained with ethidium bromide for visualization under ultraviolet light.

Statistical analysis. The associations between the VEGF variant genotypes and bladder cancer risk, tumor stage, grade and clinicopathological type were assessed using the $\chi^{2}$ test. The $\chi^{2}$ test was also used for determining the deviation from the Hardy-Weinberg equilibrium. A binary logistic regression model was used to calculate the odds ratios (ORs) and corresponding 95\% confidence intervals (CIs). All the analyses were performed with SPSS software, version 11.5 (SPSS, Inc., Chicago, IL, USA). $\mathrm{P}<0.05$ was considered to indicate a statistically significant difference.

\section{Results}

Clinical characteristics and risk factors of the study subjects. The clinical characteristics and risk factors of the patients with bladder cancer and the healthy controls are summarized in Table I. The mean age of the bladder cancer patients and that of the controls was $54.4 \pm 7.8$ and $53.6 \pm 8.4$ years, respectively. No significant differences in the mean age $(\mathrm{P}=0.46)$ or 
Table II. Vascular endothelial growth factor gene polymorphisms among bladder cancer patients and healthy controls.

\begin{tabular}{|c|c|c|c|c|c|}
\hline SNP & Genotype & Cases, $\mathrm{n}=480(\%)$ & Controls, $\mathrm{n}=420(\%)$ & OR $(95 \% \mathrm{CI})$ & P-value \\
\hline \multirow[t]{5}{*}{ rs833052 } & $\mathrm{CC}$ & 278 (57.9) & $265(63.1)$ & $0.80(0.62-1.05)$ & 0.11 \\
\hline & $\mathrm{CA}$ & $156(32.5)$ & $131(31.2)$ & $1.06(0.80-1.41)$ & 0.67 \\
\hline & $\mathrm{AA}$ & $46(9.6)$ & $24(5.7)$ & $1.75(1.05-2.92)$ & 0.03 \\
\hline & A allele frequency & $248(25.8)$ & $179(21.3)$ & $1.29(1.03-1.60)$ & 0.02 \\
\hline & $\mathrm{C}$ allele frequency & $712(74.2)$ & $661(78.7)$ & $0.78(0.62-0.97)$ & 0.02 \\
\hline \multirow[t]{5}{*}{ rs3025039 } & $\mathrm{CC}$ & $307(64.0)$ & $284(67.6)$ & $0.85(0.64-1.12)$ & 0.25 \\
\hline & $\mathrm{CT}$ & $149(31.0)$ & $121(28.8)$ & $1.11(0.84-1.48)$ & 0.47 \\
\hline & $\mathrm{TT}$ & $24(5.0)$ & $15(3.6)$ & $1.42(0.74-2.75)$ & 0.30 \\
\hline & $\mathrm{C}$ allele frequency & $763(79.5)$ & $689(82.0)$ & $0.85(0.67-1.07)$ & 0.17 \\
\hline & $\mathrm{T}$ allele frequency & $197(20.5)$ & $151(18.0)$ & $1.18(0.93-1.49)$ & 0.17 \\
\hline \multirow[t]{5}{*}{ rs 1570360} & GG & $224(46.7)$ & $213(50.7)$ & $0.85(0.65-1.11)$ & 0.23 \\
\hline & $\mathrm{AG}$ & $187(39.0)$ & $162(38.6)$ & $1.02(0.78-1.33)$ & 0.91 \\
\hline & $\mathrm{AA}$ & $69(14.3)$ & 45 (10.7) & $1.40(0.94-2.09)$ & 0.10 \\
\hline & $\mathrm{G}$ allele frequency & $635(66.1)$ & $588(70.0)$ & $0.84(0.69-1.02)$ & 0.08 \\
\hline & A allele frequency & $325(33.9)$ & $252(30.0)$ & $1.19(0.98-1.46)$ & 0.08 \\
\hline
\end{tabular}

SNP, single-nucleotide polymorphism; OR, odds ratio; CI, confidence interval.

Table III. Stratification analysis of vascular endothelial growth factor gene polymorphisms in bladder cancer.

\begin{tabular}{|c|c|c|c|c|c|c|c|c|c|c|c|c|c|c|c|c|c|c|c|}
\hline \multirow[b]{3}{*}{ Variables } & \multirow{3}{*}{$\begin{array}{l}\text { Total } \\
\text { cases }\end{array}$} & \multicolumn{6}{|c|}{ rs833052 } & \multicolumn{6}{|c|}{ rs3025039 } & \multicolumn{6}{|c|}{ rs 1570360} \\
\hline & & \multicolumn{2}{|c|}{$\mathrm{CC}$} & \multicolumn{2}{|c|}{ CA } & \multicolumn{2}{|c|}{ AA } & \multicolumn{2}{|c|}{$\mathrm{CC}$} & \multicolumn{2}{|c|}{$\mathrm{CT}$} & \multicolumn{2}{|c|}{ TT } & \multicolumn{2}{|c|}{ GG } & \multicolumn{2}{|c|}{$\mathrm{AG}$} & \multicolumn{2}{|c|}{ AA } \\
\hline & & $\mathrm{n}$ & $\mathrm{P}$ & $\mathrm{n}$ & $\mathrm{P}$ & $\mathrm{n}$ & $\mathrm{P}$ & $\mathrm{n}$ & $\mathrm{P}$ & $\mathrm{n}$ & $\mathrm{P}$ & $\mathrm{n}$ & $\mathrm{P}$ & $\mathrm{n}$ & $\mathrm{P}$ & $\mathrm{n}$ & $\mathrm{P}$ & $\mathrm{n}$ & $\mathrm{P}$ \\
\hline \multicolumn{20}{|l|}{ Tumor stage } \\
\hline Superficial & 189 & 110 & 0.92 & 58 & 0.49 & 21 & 0.36 & 113 & 0.13 & 68 & 0.06 & 8 & 0.54 & 95 & 0.20 & 68 & 0.28 & 26 & 0.76 \\
\hline Invasive & 291 & 168 & & 98 & & 25 & & 194 & & 81 & & 16 & & 129 & & 119 & & 43 & \\
\hline \multicolumn{20}{|l|}{ Tumor grade } \\
\hline Low & 338 & 202 & 0.21 & 108 & 0.69 & 28 & 0.14 & 221 & 0.32 & 102 & 0.53 & 15 & 0.39 & 153 & 0.34 & 139 & 0.13 & 46 & 0.46 \\
\hline High & 142 & 76 & & 48 & & 18 & & 86 & & 47 & & 9 & & 71 & & 48 & & 23 & \\
\hline \multicolumn{20}{|c|}{ Histological type } \\
\hline Papillary & 392 & 231 & 0.34 & 126 & 0.72 & 35 & 0.31 & 256 & 0.20 & 118 & 0.35 & 18 & 0.39 & 188 & 0.23 & 146 & 0.11 & 58 & 0.58 \\
\hline Non-papillary & 88 & 47 & & 30 & & 11 & & 51 & & 31 & & 6 & & 36 & & 41 & & 11 & \\
\hline
\end{tabular}

n, sample size; P, P-value.

gender $(\mathrm{P}=0.15)$ were observed between patients and controls. Smoking was a risk factor for bladder cancer $(\mathrm{OR}=1.48$; 95\% CI: 1.13-1.93; $\mathrm{P}=0.004)$. Among the 480 bladder cancer cases, 189 (39.4\%) were superficial (Tis-T1), 291 (60.6\%) were invasive (T2-T4), 142 (29.6\%) were high-grade (G3) and $338(70.4 \%)$ were low-grade $(\mathrm{G} 1+\mathrm{G} 2)$.

Histopathological analysis. The results of the clinical histopathological examination revealed that 392 of the samples $(81.7 \%)$ were papillary bladder cancer and 88 (18.3\%) were non-papillary bladder cancer. The majority of the bladder cancer cases were histologically diagnosed and the subjects in the control group were free from cancer. The allele distribution for the investigated VEGF gene polymorphisms did not deviate from the Hardy-Weinberg equilibrium for the bladder cancer patients or the control subjects.

Correlation of VEGF polymorphisms and bladder cancer. Our results suggested that patients with bladder cancer had a significantly higher frequency of the rs833052 AA genotype $(\mathrm{OR}=1.75 ; 95 \% \mathrm{CI}: 1.05-2.92 ; \mathrm{P}=0.03)$ compared to healthy controls (Table II). However, no statistically significant correlation was observed between the other two polymorphisms and bladder cancer risk. When stratifying by tumor stage, grade and histological type of bladder cancer, no significant associations were observed (Table III). The rs3025039 and rs1570360 gene polymorphisms were not found to be correlated with bladder cancer progression (Table III). 


\section{Discussion}

The present study aimed to investigate the correlation between VEGF gene polymorphisms and bladder cancer risk in a Chinese population. The distribution of VEGF polymorphisms in 480 patients with bladder cancer and in 420 cancer-free controls was investigated. Our results suggested that the rs833052 AA genotype was associated with a modest increase in the risk of bladder cancer in Chinese individuals.

Tobacco smoking plays a crucial role in the etiology of bladder cancer. The risk of bladder cancer in cigarette smokers is 2- to 6-fold higher compared to that in non-smokers, as several compounds in cigarettes may cause genotoxic events in the urothelium (16). Moreover, cigarette smoking was found to increase cell proliferation, as evidenced by the hyperplasia of the urinary tract epithelium (17). A previous systematic literature review reported that cigarette smoking status, frequency and duration significantly increase the risk of bladder cancer (18). Active and passive smoking, smoking amount, duration and depth of smoke inhalation were identified as risk factors for bladder cancer (19). However, although a large number of individuals are exposed to these risk factors, only a few ultimately develop bladder cancer, indicating the variation in individual susceptibility to bladder carcinogenesis $(20,21)$.

Accumulating evidence suggests that genetic polymorphisms contribute to cancer susceptibility and the clinicopathological characteristics of bladder cancer. A meta-analysis of 27 case-control studies involving a total of 15,013 subjects, conducted by Kouidhi et al (22), indicated that the C677T and A1298C polymorphisms of the methylenetetrahydrofolate reductase gene are associated with the risk and prognosis of bladder cancer. A meta-analysis of 33 case-control studies involving a total of 16,706 subjects, conducted by Jiang et al (23), suggested that glutathione S-transferase M1 mul status is associated with a significant increase in the risk of bladder cancer. Additionally, a meta-analysis of 6 case-control studies involving a total of 1,328 subjects, conducted by Li et al (24), reported that a polymorphism in p53 codon 72 is associated with bladder cancer and that the genotypic distribution of this polymorphism may vary with the stage of bladder cancer. Furthermore, a meta-analysis of 10 case-control studies involving a total of 3,549 subjects, conducted by Jiang et al (25), reported that the TP53 Arg72Pro genotype may increase the susceptibility to bladder cancer in Asian individuals. Finally, the HuGE-GSEC review, conducted by Kellen et al (26), suggested that the glutathione S-transferase P1 Ile105Val polymorphism may be associated with a modest increase in the risk of bladder cancer.

Over the last few years, several studies were conducted to investigate the association between VEGF polymorphisms and cancer risk in diverse populations; however, their results were controversial and ambiguous. Jacobs et al (27) investigated the effects of VEGF gene polymorphisms on the risk of breast cancer among postmenopausal women in America. The rs1570360 G/A VEGF polymorphism, but not rs3025039 C/T, was associated with an increased risk of breast cancer. A case-control study conducted by Rodrigues et al (28) suggested that the VEGF rs3025039 C/T genotype was likely a key genetic marker of susceptibility to breast cancer in Caucasians. The data obtained from that study also indicated that the VEGF rs833052 C/A polymorphism was not a susceptibility factor for breast cancer. A study conducted in Japan by Kawai et al (13) demonstrated that the rs1570360 G/A VEGF polymorphism was associated with the size and stage of renal tumors. However, data reported by Bruyere et al (29) did not support the association between VEGF rs1570360 G/A and the risk or prognostic parameters of renal carcinoma in an Australian population. The reasons for the variation and discrepancy among those results may include the frequency of the polymorphism, ethnic and geographic differences between the populations investigated, or linkage disequilibrium with additional, yet undiscovered, functional SNPs in the VEGF gene.

Garcia-Closas et al (15) reported the association between VEGF polymorphisms and bladder cancer risk in Spain. Consistent with our results, the results of that study revealed no association of the rs 3025039 and rs1570360 SNPs with the risk of bladder cancer and identified the rs833052 SNP as a susceptibility factor for bladder cancer. However, that study did not evaluate the correlation between these VEGF polymorphisms and bladder cancer stage, grade or histological type.

The present study was limited by the small sample size. Additionally, due to restriction of the included population, the results may not be extrapolated to other ethnic groups. Moreover, selection bias may be present due to the nature of this study (hospital-based case-control); thus, the selected subjects may not be representative of the general population.

In summary, the present study indicated that the VEGF rs 833052 C/A polymorphism may be associated with a modest increase in the risk of bladder cancer in Chinese individuals. However, further prospective and multiethnic studies, including a larger sample size, are required to confirm our findings.

\section{Acknowledgements}

This study was supported by grants from the National Natural Science Foundation of China (no. 81272823) and the Henan Science and Technology Research Foundation (no. 122102310047).

\section{References}

1. Siegel R, Naishadham D and Jemal A: Cancer statistics, 2012. CA Cancer J Clin 62: 10-29, 2012.

2. Cohen SM, Shirai T and Steineck G: Epidemiology and etiology of premalignant and malignant urothelial changes. Scand J Urol Nephrol Suppl: 105-115, 2000.

3. Steineck G, Wiholm BE and Gerhardsson de Verdier M: Acetaminophen, some other drugs, some diseases and the risk of transitional cell carcinoma. A population-based case-control study. Acta Oncol 34: 741-748, 1995.

4. Baena AV, Allam MF, Del Castillo AS, et al: Urinary bladder cancer risk factors in men: a Spanish case-control study. Eur J Cancer Prev 15: 498-503, 2006.

5. Leppert JT, Shvarts O, Kawaoka K, Lieberman R, Belldegrun AS and Pantuck AJ: Prevention of bladder cancer: a review. Eur Urol 49: 226-234, 2006.

6. Johns LE and Houlston RS: N-acetyl transferase-2 and bladder cancer risk: a meta-analysis. Environ Mol Mutagen 36: 221-227, 2000.

7. Johns LE and Houlston RS: Glutathione S-transferase mu1 (GSTM1) status and bladder cancer risk: a meta-analysis. Mutagenesis 15: 399-404, 2000.

8. Ferrara N, Gerber HP and LeCouter J: The biology of VEGF and its receptors. Nat Med 9: 669-676, 2003. 
9. Leung DW, Cachianes G, Kuang WJ, Goeddel DV and Ferrara N Vascular endothelial growth factor is a secreted angiogenic mitogen. Science 246: 1306-1309, 1989.

10. Seto T, Higashiyama M, Funai $\mathrm{H}$, et al: Prognostic value of expression of vascular endothelial growth factor and its flt- 1 and KDR receptors in stage I non-small-cell lung cancer. Lung Cancer 53: 91-96, 2006.

11. Watson CJ, Webb NJ, Bottomley MJ and Brenchley PE: Identification of polymorphisms within the vascular endothelial growth factor (VEGF) gene: correlation with variation in VEGF protein production. Cytokine 12: 1232-1235, 2000.

12. Bae SJ, Ahn DH, Hong SP, et al: Gender-specific association between polymorphism of vascular endothelial growth factor (VEGF 936C >T) gene and patients with stomach cancer. Yonsei Med J 49: 783-791, 2008.

13. Kawai Y, Sakano S, Korenaga Y, Eguchi S and Naito K: Associations of single nucleotide polymorphisms in the vascular endothelial growth factor gene with the characteristics and prognosis of renal cell carcinomas. Eur Urol 52: 1147-1155, 2007.

14. Zhou Y, Li N, Zhuang W and Wu X: Vascular endothelial growth factor (VEGF) gene polymorphisms and gastric cancer risk in a Chinese Han population. Mol Carcinog 50: 184-188, 2011.

15. Garcia-Closas M, Malats N, Real FX, et al: Large-scale evaluation of candidate genes identifies associations between VEGF polymorphisms and bladder cancer risk. PLoS Genet 3 : e29, 2007.

16. Brennan $\mathrm{P}$, Bogillot $\mathrm{O}$, Cordier $\mathrm{S}$, et al: Cigarette smoking and bladder cancer in men: a pooled analysis of 11 case-control studies. Int J Cancer 86: 289-294, 2000.

17. Johansson SL and Cohen SM: Epidemiology and etiology of bladder cancer. Semin Surg Oncol 13: 291-298, 1997.

18. Zeegers MP, Kellen E, Buntinx F and van den Brandt PA: The association between smoking, beverage consumption, diet and bladder cancer: a systematic literature review. World J Urol 21 : 392-401, 2004

19. Dai QS, He HC, Cai C, et al: Multicenter case-control study of the relationship between smoking and bladder cancer in China Zhonghua Yi Xue Za Zhi 91: 2407-2410, 2011 (In Chinese).
20. Manolio TA, Brooks LD and Collins FS: A HapMap harvest of insights into the genetics of common disease. J Clin Invest 118: 1590-1605, 2008

21. Rahim NG, Harismendy O, Topol EJ and Frazer KA: Genetic determinants of phenotypic diversity in humans. Genome Biol 9: 215, 2008.

22. Kouidhi S, Rouissi K, Khedhiri S, Ouerhani S, Cherif M and Benammar-Elgaaied A: MTHFR gene polymorphisms and bladder cancer susceptibility: a meta-analysis including race, smoking status and tumour stage. Asian Pac J Cancer Prev 12: 2227-2232, 2011

23. Jiang Z, Li C and Wang X: Glutathione S-transferase M1 polymorphism and bladder cancer risk: a meta-analysis involving 33 studies. Exp Biol Med (Maywood) 236: 723-728, 2011.

24. Li DB, Wei X, Jiang LH, Wang Y and Xu F: Meta-analysis of epidemiological studies of association of P53 codon 72 polymorphism with bladder cancer. Genet Mol Res 9: 1599-1605, 2010.

25. Jiang DK, Ren WH, Yao L, Wang WZ, Peng B and Yu L: Meta-analysis of association between TP53 Arg72Pro polymorphism and bladder cancer risk. Urology 76: 765.e1-765.e7, 2010.

26. Kellen E, Hemelt M, Broberg K, et al: Pooled analysis and meta-analysis of the glutathione S-transferase P1 Ile105Val polymorphism and bladder cancer: a HuGE-GSEC review. Am J Epidemiol 165: 1221-1230, 2007.

27. Jacobs EJ, Feigelson HS, Bain EB, et al: Polymorphisms in the vascular endothelial growth factor gene and breast cancer in the Cancer Prevention Study II cohort. Breast Cancer Res 8: R22, 2006.

28. Rodrigues P, Furriol J, Tormo E, Ballester S, Lluch A and Eroles P: The single-nucleotide polymorphisms $+936 \mathrm{C} / \mathrm{T}$ VEGF and -710 C/T VEGFR1 are associated with breast cancer protection in a Spanish population. Breast Cancer Res Treat 133: 769-778, 2012.

29. Bruyere F, Hovens CM, Marson MN, et al: VEGF polymorphisms are associated with an increasing risk of developing renal cell carcinoma. J Urol 184: 1273-1278, 2010. 